\title{
A Gray-purple Mass on the Floor of the Mouth: Gigantic Mucogingival Pyogenic Granuloma in a Teenage Patient
}

\author{
Lluís Brunet-LLobet ${ }^{1}$, Jaume Miranda-Rius ${ }^{2, *}$, Eduard Lahor-Soler ${ }^{2}$, Ombeni Mrina ${ }^{3}$ and Alfons \\ $\mathrm{Nadal}^{4}$ \\ ${ }^{l}$ Servei d'Odontopediatria, Hospital Universitari Sant Joan de Déu, Universitat de Barcelona, Barcelona, Spain \\ ${ }^{2}$ Departament d'Odontostomatologia, Facultat d'Odontologia, Universitat de Barcelona, Barcelona, Spain \\ ${ }^{3}$ Dental \& Oral Department, Soweto General Hospital, Arusha, United Republic of Tanzania \\ ${ }^{4}$ Servei d'Anatomia Patològica, Hospital Clínic, Universitat de Barcelona, Barcelona, Spain
}

\begin{abstract}
Pyogenic granuloma is defined as a benign neoplasm of vascular phenotype. This case describes the clinical and histopathological features of a gigantic mucogingival pyogenic granuloma, in a 14-year-old healthy black boy. This exophytic gray-purple mass, related to a toothpick injury, had more than twelve-month evolution on the anterior mandible involving lingual area besides to the floor of the mouth pressing the right salivary duct. Conservative excision was performed, followed by uncomplicated healing with no recurrence in two years. The histopathological examination reported a pyogenic granuloma (lobular capillary haemangioma). The authors provide a discussion of the presurgical differential diagnosis of the lesion. This case report presents an extremely uncommon location of a gigantic pyogenic granuloma, involving mucogingival complex and affecting the salivary outflow. This clinical manuscript may shed light on the controversies about possible mechanisms inducing oral pyogenic granuloma.
\end{abstract}

Keywords: Inflammatory gingival hyperplasia, lobular capillary haemangioma, mucogingival complex, pyogenic granuloma.

\section{INTRODUCTION}

Soft tissue enlargements of the oral cavity often present a diagnostic challenge because a diverse group of pathologic processes can produce such lesions. Enlargement may be the result of a variation of normal anatomic structures, inflammation, cysts, developmental anomalies, and neoplasms [1, 2].

Pyogenic granuloma $(\mathrm{PG})$ is defined by several authors just as an inflammatory hyperplasia characterised by inflamed fibrous and granulation tissues, while for others PG is a common tumour-like growth of the oral cavity or skin that is considered to be non-neoplastic in nature $[3,4]$.

The lesion is believed to originate as aggravated tissue response to trivial trauma. Although the most common intraoral site is on the buccal gingiva, PG has been reported at other sites, including lips, tongue and oral mucosa [5].

PG may occur at any age, albeit some authors indicate that patients are mostly males under 18 years of age, females in the age range 18 to 39 , and older patients with an equal gender distribution. PG is the most common localized enlargement in the oral cavity showing a striking predilection

*Address correspondence to this author at the Departament d'Odontostomatologia, Facultat d'Odontologia, Universitat de Barcelona. Feixa Llarga, s/n, 08907 L'Hospitalet de Llobregat, Barcelona, Spain;

Tel: +34 934024 269; Fax: +34 934035 558;

E-mail: jmiranda-rius@ub.edu for the gingiva, accounting for $75 \%$ of all cases. These lesions are much more common on the buccal than the lingual gingiva, some extend between the teeth but the majority are found on the marginal gingiva $[3,5]$.

Exact etiopathogenesis of PG is not clearly understood, but vascular morphogenetic factors were found in comparison to healthy gingiva. Various theories have been proposed: hormonal influence plays a role in pregnant women (through estrogen and progesterone) whereas trauma can cause releasing of various endogenous substances including angiogenic factors $[1,4,6]$.

This case report describes a very rare presentation of a PG, lobular capillary hemangioma, in a teenage patient and the histopathology of this lesion.

\section{CASE REPORT}

A 14-year-old black boy was attended, through a collaborative program supported by a not-for-profit program, at Dental \& Oral Department in Soweto General Hospital Arusha - (Tanzania). The chief complaint was a growing mass on the floor of the mouth for more than one year, which increased in size in the last weeks (Fig. 1). The lesion was asymptomatic although its considerable size had a potential to affect speech, mastication and even displacement of the neighbouring teeth. The patient referred a previous toothpick traumatic injury where the lesion appeared. There was neither past dental nor medical history of note. 


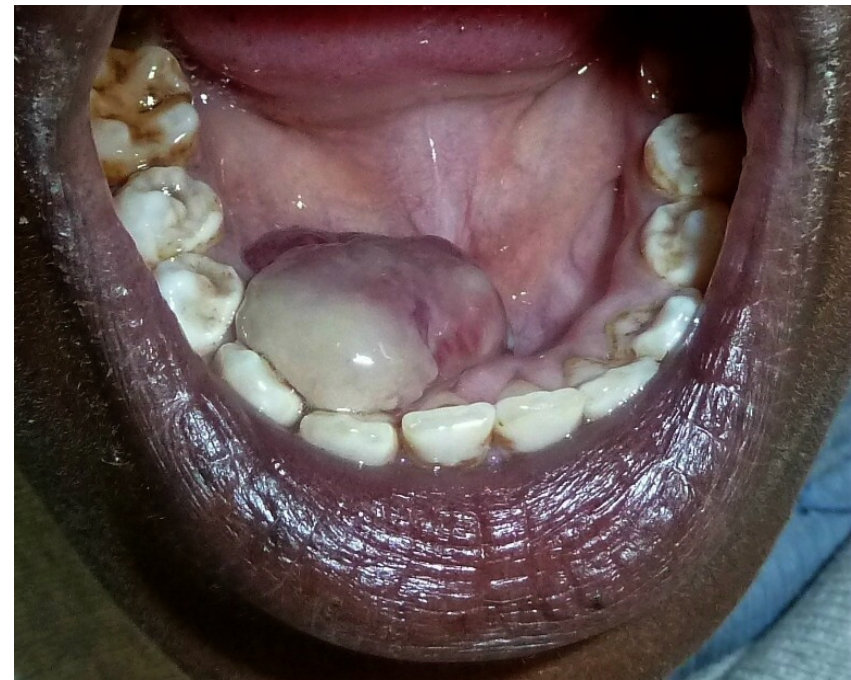

Fig. (1). Clinical intraoral image of the exophytic lesion in relation to lingual area.

The oral examination confirmed a rather good dental hygiene without caries or periodontitis. Only occasional slight bleeding was registered on the periodontal charting. No dental mobility was noted and dental vitality was normal. There was not any palpable submandibular adenopathy either.

An exophytic kidney-shaped lesion with a lobular contour and a glossy gray to reddish-purple surface measuring 25 to $30 \mathrm{~mm}$ in diameter was located in the anterior lingual right jaw, inserted through a pedunculated base on the keratinized mucosa also involving the mucogingival line (Fig. 2). The mass was painless on palpation with a smooth compressible surface but with certain firm doughy consistence. A routine periapical radiograph showed normal alveolar bone trabeculation without root resorption.

A conservative surgical excision of the lesion was planned. After local anaesthesia, the pedunculated mass was completely excised through the base of the lesion. A careful management of the lesion was performed while preserving the mucogingival complex. The underlying tissue was curetted to prevent recurrence of the lesion before suturing. Antibiotics and analgesics were prescribed for one week. After the excision of this pedunculated mass, a light and asymptomatic tumefaction was clearly evidenced on the right sublingual area probably related with the compressive effect on the right salivary duct (Fig. 3a, b). This swelling disappeared in a week after surgery.

The excised tissue was submitted for histopathological analysis. Histopathology showed a highly vascular proliferation, with blood vessels organised in lobular aggregates, consistent with lobular capillary hemangioma. At low magnification each lobule is surrounded by a thin collagen layer. At a higher magnification the small capillary endothelial-lined spaces are surrounded by a perithelial or pericytic layer of cells. Chronic inflammatory cells are consistently present throughout the edematous stroma. The final pathological diagnosis based on the microscopic findings was a pyogenic granuloma-lobular capillary hemangioma (Fig. 4a, b).

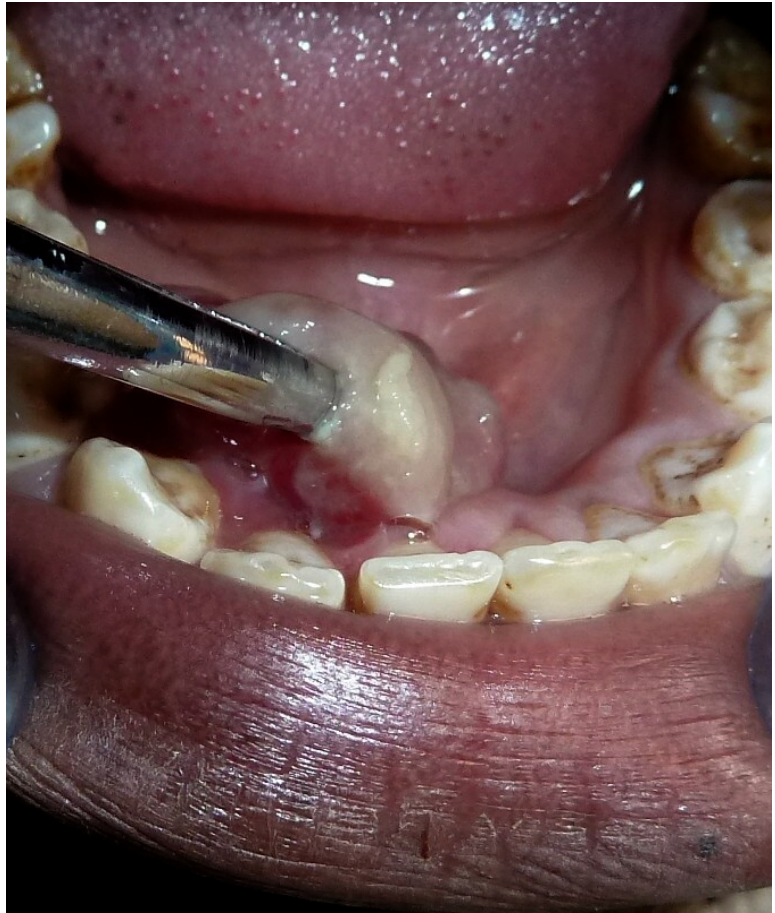

Fig. (2). Clinical intraoral image. The lesion was pedunculated involving the lingual mucogingival line and inserted on the keratinized mucosa.

With the diagnosis of PG the patient and his mother were questioned again about any previous oral wound. A toothpick injury in the same area where mass appeared, was confirmed.

The patient was monitored postoperatively and two years later, the gingival tissue and the adjacent alveolar mucosa were healthy with successful healing without recurrence.

\section{DISCUSSION}

PG is defined as a benign neoplasm of vascular phenotype. However, many authors agree that this lesion is the result of an exaggerated localized connective tissue reaction to a minor injury or any underlying irritation $[7,8]$. Several "etiologic factors" have been suggested such as trauma, chronic irritation, hormones, drugs, gingival inflammation, pre-existing vascular lesions, exfoliation of primary teeth, eruption of permanent teeth, defective fillings in the region of tumour, food impaction or presence of a foreign object or material $[1,3,9]$. In our case, PG could be attributed to a toothpick injury on the lingual gingiva.

Clinically, PG generally presents as a smooth or lobulated exophytic lesion with either a pedunculated or a sessile base. Although its size can range from a few millimetres to several centimetres, it rarely exceeds more than $3 \mathrm{~cm}[7,10$, 11]. The surface of the lesion may undergo secondary, nonspecific changes that include ulceration, stromal edema, capillary dilation, inflammation and granulation tissue reaction. Some scarring may be noted in some of PG, suggesting that occasionally there may be maturation of the connective tissue repair process [12]. 

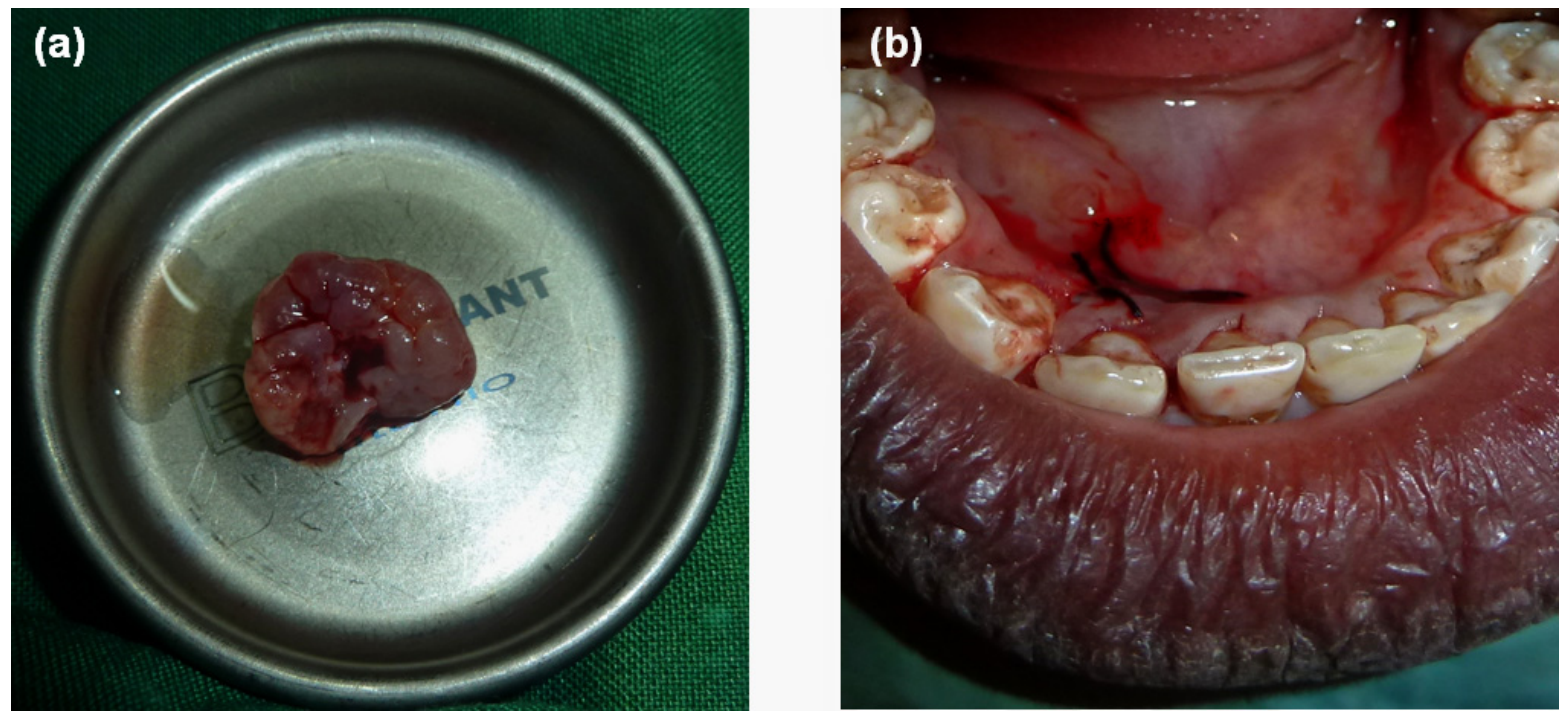

Fig. (3a). Macroscopic appearance of the excised lesion. Notice the multilobular base around the pedunculated area.

(b). Clinical intraoral image. Notice a light tumefaction evidenced on the right sublingual area, immediately after the mass excision.
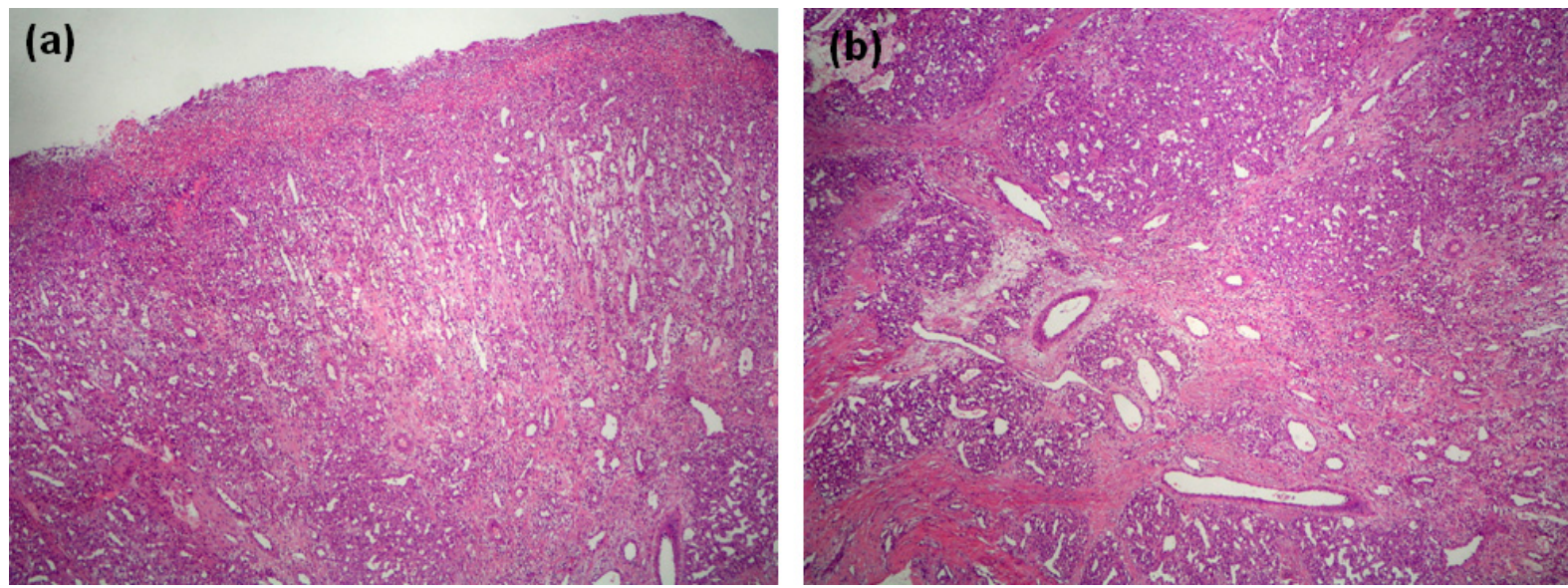

Fig. (4a). Microscopic appearance. Under an ulcerated surface there is an extensive granulation tissue reaction characterized by abundant small size vessels arranged perpendicularly to surface. At the bottom of the image, the characteristic appearance of pyogenic granuloma can be seen on the right (H\&E, original magnification 10x).

(b). At a higher power, the typical histologic features of pyogenic granuloma consist in a proliferation of capillary sized vessels arranged surrounding larger vessel structures producing its typical lobular distribution. There is stromal fibrosis dissecting between the capillary lobules. (H\&E, original magnification 20x).

The term pyogenic is a misnomer that leads to confusion as, in fact, the lesion is not of infectious etiology. However, the PG surface may eventually ulcerate and be replaced by a thick fibrinoleukocytic exudate. A mixed inflammatory cell infiltrate of neutrophils is mostly prevalent near the ulcerated surface; chronic inflammatory cells are found deeper in the specimen [3]. Histologically, PG is partly or completely covered by parakeratotic or non-keratinized stratified squamous epithelium, the amount of collagen in the connective tissue being usually sparse [1]. Microscopic examination of PG shows a highly vascular proliferation that resembles granulation tissue [13]. The blood vessels often show a clustered or lobular pattern separated by less vascular fibrous septa, leading some authors to consider PG as a polypoid form of capillary hemangioma or nothing more than an inflamed lobular hemangioma; others prefer to use the term granulation tissuetype hemangioma [14]. As in our case, some pathologists re- quire these vessels organised in lobular aggregates to make the diagnosis of lobular capillary hemangioma $[13,15]$.

According to the clinical presentation and taking into account patient demographic features, the presurgical differential diagnosis of this gray-purple mass was basically structured in the following additional entities: peripheral giant cell granuloma, peripheral ossifying fibroma, fibroma, peripheral odontogenic fibroma, infantile hemangioma, conventional granulation tissue, hyperplastic gingival inflammation, Kaposi's sarcoma, bacillary angiomatosis, angiosarcoma and Non Hodgkin's lymphoma [3, 16-18].

Foreign body reaction (FBR) is other differential diagnosis that should be considered. The presence of foreign bodies in the oral mucosa is considered rare although some materials such as wood, fingernail, and toothbrush bristles are reported. On the other hand, fish bones are the most common 
cause of these lesions in the tonsil, soft palate, tongue base, posterior pharyngeal wall and upper oesophagus. Oral granuloma due to on FBR is frequently accompanied at early stages by pain, swelling, local infection around the foreign body and history of oral trauma $[17,19]$.

For PG, surgical excision is the treatment of choice. After surgical excision of gingival lesions, curettage of underlying tissue is recommended [4, 7, 20, 21]. Other proposed conservative techniques like cryosurgery, electrodessication and sclerotherapy are also used [22, 23]. However, a more recent protocol is focused on the use of laser surgery by flash lamp pulsed dye laser and especially Nd: YAG laser because of its superior coagulation characteristics over $\mathrm{CO}_{2}$ laser $[24,25]$. After excision, recurrence occurs in up to $16 \%$ of the lesions, making re-excision necessary. Recurrence is believed to result from incomplete excision, failure to remove etiologic factors, or re-injury of the area [26]. It should be emphasised that gingival cases show a much higher recurrence rate than lesions from other oral mucosal sites [4].

\section{CONCLUSION}

This manuscript is interesting because describes a very rare presentation of gigantic lobular capillary hemangioma, associated with a traumatic injury in a teenage patient. Lingual area location, besides the floor of the mouth pressing the salivary secretory duct, is extremely uncommon. A careful management of the lesion should be performed while preserving the mucogingival complex. To our knowledge, in the literature there are no previous cases of pyogenic granuloma with these clinical features.

\section{CONFLICT OF INTEREST}

The authors confirm that this article content has no conflicts of interest.

\section{ACKNOWLEDGEMENTS}

Clínics Associates, a well-established Professional Partnership in Terrassa (Barcelona), deserves a special mention for leading and supporting KiliBarna Dental project at Soweto General Hospital in Arusha, United Republic of Tanzania, East Africa. The authors thank Miguel Torres Foundation and Straumann, SA (Spain) for their contributions.

\section{REFERENCES}

[1] Kamal R, Dahiya P, Puri A. Oral pyogenic granuloma: various concepts of etiopathogenesis. J Oral Maxillofac Pathol 2012; 16(1): 79-82.

[2] Miranda Rius J, Nadal A, Lahor E, Mtui B, Brunet L. Unusual presentation of localized gingival enlargement associated with a slow-growing odontogenic myxoma. Int J Oral Sci 2013; 5:172-5.

[3] Jafarzadeh H, Sanatkhani M, Mohtasham N. Oral pyogenic granuloma: a review. J Oral Sci 2006; 48(4): 167-75.
[4] Vilmann A, Vilmann P, Vilmann H. Pyogenic granuloma: evaluation of oral conditions. Br J Oral Maxillofac Surg 1986; 24(5): 376-82.

[5] Pagliai KA, Cohen BA. Pyogenic granuloma in children. Pediatr Dermatol 2004; 21(1): 10-3.

[6] Yih WY, Richardson L, Kratochvil FJ, et al. Expression of estrogen receptors in desquamative gingivitis. J Periodontol 2000; 71(3): $482-7$

[7] Saravana GH. Oral pyogenic granuloma: a review of 137 cases. $\mathrm{Br}$ J Oral Maxillofac Surg 2009; 47(4): 318-9.

[8] Verma PK, Srivastava R, Baranwal H, et al. Pyogenic granulomahyperplastic lesion of the gingiva: case reports. Open Dent J 2012; 6: 153-6.

[9] Mathur LK, Bhalodi AP, Manohar B, et al. Focal fibrous hyperplasia: a case report. Int Dent Clin 2010; 2(4): 56-7.

[10] Yuan K, Jin YT, Lin MT. Expression of Tie-2, angiopoietin-1, angiopoietin-2, ephrinB2 and ephrinB4 in pyogenic granuloma of human gingival implicates in their roles in inflammatory angiogenesis. J Periodontol Res 2000; 35(3): 165-71.

[11] Ong MA, Chai WL, Ngeow WC. Recurrent gigantic pyogenic granuloma disturbing speech and mastication: a case report and literature review. Ann Acad Med Singapore 1998; 27: 258-61.

[12] Willies Jacobo LJ, Isaacs H Jr., Stein MT. Pyogenic granuloma presenting as a congenital epulis. Arch Pediatr Adolesc Med 2000; 154(6): 603-5.

[13] Neville BW, Damm DD, Allen CM, Bouquot JE. Oral \& maxillofacial pathology. $2^{\text {nd }}$ ed, WB Saunders: Philadelphia 2002; pp. 437-95.

[14] Bouquot JE, Nikai H. Lesions of the oral cavity. In: Diagnostic surgical pathology of the head and neck. Gnepp DR. Ed, 2001. WB Saunders: Philadelphia, 2001; pp. 141-233.

[15] Fechner RE, Cooper PH, Mills SE. Pyogenic granuloma of the larynx and trachea: a causal and pathologic misnomer for granulation tissue. Arch Otolaryngol 1981; 107: 30-2.

[16] Motamedi MH, Eshghyar N, Jafari SM, et al. Peripheral and central giant cell granulomas of the jaws: a demographic study. Oral Surg Oral Med Oral Pathol Oral Radiol Endod 2007; 103(6): e39-43.

[17] Chen H, Zhao Z, Gong X, et al. A tongue granuloma due to a fishbone mimicking a neoplasm: ultrasound-guided differential diagnosis. Ultraschall Med 2011; 32 (Suppl 1): S1-2.

[18] Gouvêa AF, Hanemann JA, Pereira AA, et al. Uncommon foreign body reactions occurring in the lip: clinical misdiagnosis and the use of special techniques of analysis. Head Neck 2011; 5(1): 86-91.

[19] Fatahzadeh M. Kaposi sarcoma: review and medical management update. Oral Surg Oral Med Oral Pathol Oral Radiol 2012; 113(1): 2-16.

[20] Epivanatos A, Antoniades D, Zaraboukas T, et al. Pyogenic granuloma of the oral cavity: comparative study of its clinicopathological and immunohistochemical features. Pathol Int 2005; 55(7): 391-7.

[21] Patil K, Mahima VG, Lahari K. Extragingival pyogenic granuloma. Indian J Dent Res 2006; 17(4): 199-202.

[22] Ichimiya M, Yoshikawa Y, Hamamoto $\mathrm{Y}$, et al. Successful treatment of Pyogenic granuloma with injection of absolute ethanol. $\mathrm{J}$ Dermatol 2004; 31(4): 342-4.

[23] Moon SE, Hwang EJ, Cho KH. Treatment of pyogenic granuloma by sodium tetradecyl sulphate sclerotherapy. Arch Dermatol 2005 , 141(5): 644-6.

[24] Powell JL, Bailey CL, Coopland AT, et al. Nd: YAG laser excision of a giant gingival pyogenic granuloma of pregnancy. Lasers Surg Med 1994; 14(2): 178-83.

[25] Meffert JJ, Cagna DR, Meffert RM. Treatment of oral granulation tissue with the flashlamp pulsed dye laser. Dermatol Surg 1998; 24(8): $845-8$.

[26] Toida M, Hasegawa T, Watanabe F, et al. Lobular capillary hemangioma of the oral mucosa: clinicopathological study of 43 cases with a special reference to immunohistochemical characterization of the vascular elements. Pathol Int 2003; 53(1): 1-7.

(C) Brunet-LLobet et al.; Licensee Bentham Open .

This is an open access article licensed under the terms of the Creative Commons Attribution Non-Commercial License (http://creativecommons.org/licenses/by-nc/3.0/) which permits unrestricted, non-commercial use, distribution and reproduction in any medium, provided the work is properly cited. 